\title{
Congenital Heart Diseases Impair Female Fertility
}

\author{
Shao-Ju Chien ${ }^{1,2 *}$, Ying-Jui Lin ${ }^{1}$, Mao-Hung Lo ${ }^{1}$, Chien-Fu Huang ${ }^{1}$ and Yao-Hsu Yang ${ }^{3,4,5}$ \\ ${ }^{1}$ Department of Pediatrics, Kaohsiung Chang Gung Memorial Hospital and College of Medicine, Chang Gung University, \\ Kaohsiung, Taiwan, ${ }^{2}$ Department of Early Childhood Care and Education, Cheng Shiu University, Kaohsiung, Taiwan, ${ }^{3}$ Health \\ Information and Epidemiology Laboratory of Chang Gung, Memorial Hospital Chiayi, Chiayi, Taiwan, ${ }^{4}$ Department of \\ Traditional Chinese Medicine, Chang Gung Memorial, Hospital Chiayi, Chiayi, Taiwan, ${ }^{5}$ School of Traditional Chinese \\ Medicine, College of Medicine, Chang Gung University, Taoyuan, Taiwan
}

OPEN ACCESS

Edited by:

Mauro Lo Rito,

IRCCS Policlinico San Donato, Italy

Reviewed by:

Alvise Guariento,

Hospital for Sick Children, Canada Marie-Christine Seghaye, University Hospital Center of Liège, Belgium

*Correspondence:

Shao-Ju Chien ma4695@gmail.com

Specialty section:

This article was submitted to

Pediatric Cardiology,

a section of the journal

Frontiers in Pediatrics

Received: 29 March 2021

Accepted: 11 June 2021

Published: 14 July 2021

Citation:

Chien S-J, Lin Y-J, Lo M-H, Huang C-F and Yang Y-H (2021) Congenital Heart Diseases Impair

Female Fertility.

Front. Pediatr. 9:687276.

doi: 10.3389/fped.2021.687276
Background: The objective of this research was to evaluate the fertility of Taiwanese women with diagnoses of congenital heart diseases (CHDs). The study also investigated how different forms of CHDs may have variously influenced fertility.

Methods: We directed this nationwide, population-based and retrospective matched-cohort research by using data from the Taiwan National Health Insurance Research Database. The CHD group $(n=6602)$ included women with congenital structural heart diseases, aged 16-45 years in 2000. The non-CHD group ( $n=6602)$ was matched according to urbanization and income. The outcomes, involving live birth, abortion, and fertility rates, were followed until the end of 2013. Poisson regression was used to evaluate the incidence rate ratios (IRRs).

Results: The CHDs had an inferior rate of live births (IRR 0.74 [95\% Cl 0.71-0.78]) than the non-CHD group. There was also a lower fertility rate in the CHD group (IRR 0.81 [95\% $\mathrm{Cl} 0.78-0.84]$ ) than the non-CHD group. Abortion rates between the two groups were similar.

Conclusion: Congenital structural heart disease compromises female fertility, even among patients with simple forms of CHDs. It is suggested that pregnant patients with CHDs are early appeared to and advised personally with multidisciplinary care to improve their outcomes.

Keywords: fertility, abortion, congenital heart disease, national health insurance research database, live births

\section{INTRODUCTION}

As a result of advances in cardiac surgery and pediatric medical care, more children with congenital heart diseases (CHDs) have reached grown-up in the past decades, than in any history. Only $20 \%-30 \%$ of children with CHDs survived into parenthood 50 years ago, but, today, over $90 \%$ survive long-term. In turn, the adult CHDs population is steadily growing, even for patients with the most complex lesions $(1,2)$. According to Wu's study, based on the Taiwan National Health Insurance Research Database, the event-free survival rate (95\% confidence interval [95\% CI]) of all children with CHDs in Taiwan was 95.1\% (94.5-95.4\%). Even among patients with severe CHDs, the overall survival rate was $76.4 \%$, with survival rates of $87.8 \%$ and $66.7 \%$ for tetralogy of Fallot and transposition of the great arteries patients, respectively (3). An increasing number of women with CHDs thrive well into their childbearing years. Expecting increased quality of life, affected women often express a desire to start a family, containing giving birth to children, despite possible cardiac complications caused by the hemodynamic alterations associated with pregnancy (4). Although the majority of pregnancies do not lead to major complications in women with CHDs, the amount of 
risk for both mother and newborn increases concurrently with the complexity of the underlying heart anomaly $(2,5,6)$. Pregnancy will hazard their life of women with CHDs with an increased risk (18\%) of fetal and neonatal complications in comparison with healthy women (7\%) (7).

The 2011 guidelines of the European Society of Cardiology on the management of cardiovascular diseases during pregnancy, sketch some risk factors of neonatal miscarriage and perinatal mortality that include maternal structural heart diseases (8-11). However, it is unknown whether maternal CHDs is associated with more miscarriages or stillbirths. Besides, women with pulmonary hypertension have a high risk during pregnancy and associated with high morbidity and mortality in all defined clinical groups of pulmonary hypertension (12). The purpose of this nationwide retrospective cohort study was to investigate the fertility rate of women with CHDs, focusing on their live births, abortions, and fertility. We also investigated how different forms of CHDs and the presence of pulmonary hypertension may have variously influenced the observed fertility rate. To our knowledge, the current study is the first to provide an impression of live birth, abortion, and fertility rates, based on data from a large, national database of women with CHDs, and to include a comparison of the different forms of CHDs.

\section{METHODS}

\section{Source of Datasets}

The research data were retrieved from the National Health Insurance Research Database (NHIRD). Taiwan government launched a single-payer National Health Insurance (NHI) program on March 1, 1995 and the coverage rate is around 99\% of the population by the end of 2014. The NHIRD contains all deidentified registration files and original medical claims data from the NHI program. The completeness and accuracy of NHIRD have been reported and acceptable, and it has been used in previous research of CHDs (3). This study was approved by the Institutional Review Board of Chang Gung Medical Foundation (IRB No. 1906140058).

\section{Matched Cohort Design}

We searched for female patients with CHDs in the NHIRD across the 1997-2013 range according to the International Classification of Diseases 9th Revision, Clinical Modification [ICD-9-CM] codes of 745.xx, 746.xx, 747.xx to 747.49. Patients with CHDs also had catastrophic illness/injury certificates (CICs). Taiwan National Health Insurance Administration issues a CIC to patients with $\mathrm{CHDs}$ except some insignificant or spontaneously resolved cardiac defects. Cardiologists or pediatric cardiologists approve the CHD diagnosis according to patients' clinical manifestations and echocardiographic reports before issuing a CIC. The research excluded patients younger than 16 years or older than 45 years in 2000 to ensure that the study subjects were entirely within reproductive age during the research period. The date when the CIC was issued was considered as the date of a diagnosis of CHD.

Matched subjects, without CHDs, were found by searching the Longitudinal Health Insurance Database of 2000 (LHID2013). These subjects were matched one-to-one with CHD subjects for age, gender, income, and urbanization rate. The LHID is a subset of the NHIRD and contains 1,000,000 randomly sampled beneficiaries from 2000. It constitutes about $5 \%$ of Taiwan's population and its gender distribution does not differ significantly from that of the NHIRD. Incomes were classified into four groups: $0,1-15840,15840-25000$, and $>25000 \mathrm{New}$ Taiwan dollars per month. Urbanization levels were classified as very high, high, moderate, and low. The accessibility and availability of health care will be affected by these factors. Female infertility (ICD-9-CM code 628) listed in the leading five diagnoses in any outpatient or inpatient medical records was recognized as a confounding factor. The flow chart of case selection and exclusion is shown in Figure 1.

\section{Outcomes and Risk Factors}

The study outcomes involved live birth, abortion, and fertility rates. Live birth was defined as a normal vaginal delivery in the inpatient diagnosis with or without complications (NHI codes: 97001A, 97001K, 97002A, 97003B, 97004C, 97005D, 97931K, 97932A, 97933B, 97934C, 81017C, 81024C, and 81034C). Besides a cesarean delivery (NHI codes: 97006K, 97007A, 97008B, 97009C, 97014C, 98001K, 98002A, 98003B, 98004C, 81004C, $81005 \mathrm{~B}, 81005 \mathrm{C}, 81028 \mathrm{C}$, and $81029 \mathrm{C})$, or a multifetal pregnancy (NHI codes: 81018C, 81019C, 81025C, and 81026C) were also included (13). Abortion was defined as ICD-9-CM codes of $632,633,634$, and 637 in the first five diagnoses of inpatient and ambulatory claims (14). The diagnosis of abortion with an interval in excess of 1 month and 10 months for an ectopic pregnancy were regarded as separate events. Total numbers of live births and abortions was defined as fertility. Outcomes were followed until the end of the study period or death.

Various cardiac structural defects were also investigated as potential factors affecting fertility rates. The recommended parameters from the American College of Cardiology were used to classify levels of disease severity. According to the college's modified forms, simple CHD patients are those who can typically be cared for by the general medical community, while patients with severe CHDs are those who should be seen regularly at centers with physicians experienced in administering care for CHD patients (15). Because the 2011 guidelines of the European Society of Cardiology define maternal left heart obstruction and single ventricle physiology as high or very high risk factors for neonatal complications (10), the left-sided heart lesions and single ventricle groups were all classified into severe CHD group for data analysis. To avoid errors caused by incorrect tentative diagnosis and miscoding, we searched for CHD diagnoses in the top five diagnoses of inpatient claims among those patients with CICs of CHDs. All CHDs were classified into the two forms according to their cardiac structural defects. According to Wu's Taiwanese national population studies in 2010 and 2015, the codes encompassing "simple" CHDs, included secundum atrial septal defects (7455), ventricular septal defects (7454), patent ductus arteriosus (7470), pulmonary stenosis/anomalies (74602), and partial anomalous pulmonary venous connections (74742). The diagnostic codes comprising "severe" CHD were common truncus $(7450,74500)$, transposition of great vessels/congenitally corrected transposition of great arteries $(7451,74510,74512)$, tetralogy of Fallot (7452), common ventricle (7453), endocardial 


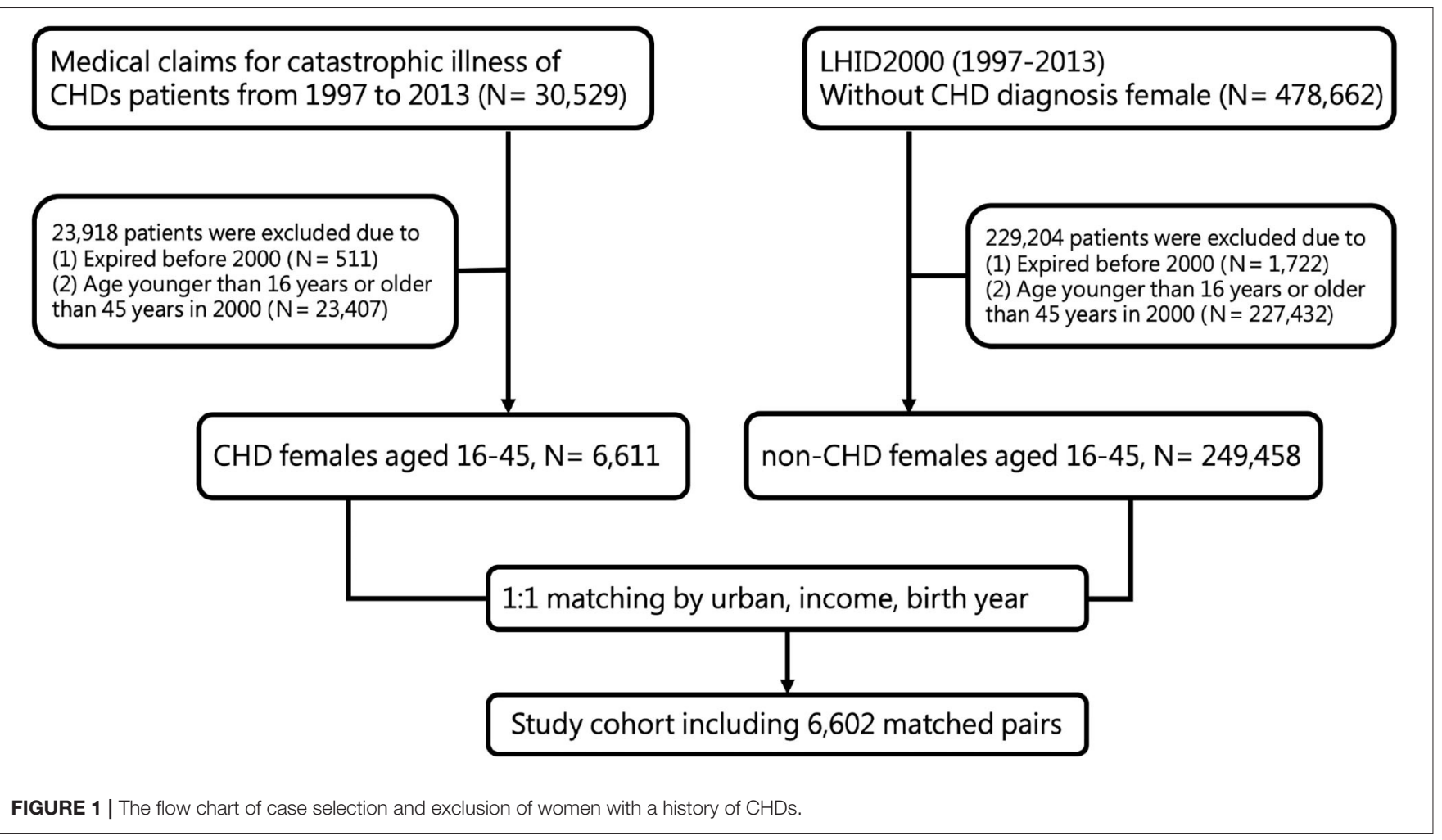

cushion defects $(7456,74560,74569)$, anomalies of pulmonary valve/artery $(7460,7473,74600,74601,74609)$, tricuspid atresia and stenosis (7461), Ebstein's anomaly (7462), congenital stenosis or insufficiency of mitral or aortic valve (7463, 7464, 7465, $7466)$, subaortic stenosis (74681), coarctation of the aorta or anomalies of aorta $(7471,74710,74711,7472,74720,74721$, $74722,74729)$, double outlet right ventricle (74511), common atrium (74561), cor triatriatum (74682), infundibular pulmonic stenosis (74683), coronary artery anomaly (74685), congenital heart block (74686), total anomalous pulmonary venous return (74741) and hypoplastic left heart syndrome $(7467)(3,16)$. Pulmonary hypertension was defined as ICD-9-CM codes of 4160, 4168 and 4169 (17).

\section{Statistical Analyses}

The distribution of demographic data and the proportions of different CHDs were compared between patients with and without CHDs. We calculate the incidence rate per 10,000 person-years as IR. Poisson regression was used to assess incidence rate ratios (IRRs) and the corresponding 95\% confidence interval (CI) of live births, abortions, and fertility rates between the patients with and without CHDs. To investigate the influence of different structural defects, severity levels and pulmonary hypertension on fertility in female patients with CHDs, we compared IRRs within the CHD groups, according to their structural complexity and association. All analyses were conducted by means of SAS statistical software (version 9.4; SAS Institute, Cary, NC, USA).

\section{RESULTS}

\section{Characteristics of the Study Subjects}

The characteristics and comparisons of the 6,602 study subjects and 6,602 age-, income-, and urbanization-matched non-CHD subjects from the LHID are shown in Table 1. We also regarded their underlying infertility probably as confounding factor, their diagnoses of female infertility in past medical records were also compared without significant differences between the CHD and non-CHD groups. Fertility frequencies of $0,1,2$, and $\geq 3$ in the $\mathrm{CHD}$ and non-CHD groups during the research period were 66 , 15,12 , and $8 \%$ vs. $59,16,14$, and $11 \%$, respectively.

\section{Live Births, Abortions, and Fertility Rates of CHD and Non-CHD Patients}

The study population was composed of 6,602 patients who were diagnosed with CHDs and were 16-45 years of age. The comparison of live births, abortions and fertility rate between CHD and non- CHD patients are demonstrated in Table 2. Of these women, 2,270 had a total of 2,835 live births. There were fewer live births in CHD patients (IRR 0.74, 95\% CI 0.71-0.78, $p$ $<0.001)$. The number of abortions was comparable between the $\mathrm{CHD}$ and non-CHD groups. As a result, fertility was inferior in the CHD group (IRR 0.81, 95\% CI 0.78-0.84, $p<0.001$ ).

\section{Distribution of Forms of Congenital Heart Diseases}

The underlying congenital heart lesions, the number of patients affected by each, the associated ICD-9-CM codes, and the 
TABLE 1 | Characteristics of the study subjects.

\begin{tabular}{|c|c|c|c|c|c|}
\hline \multirow[t]{2}{*}{ Variables } & \multicolumn{2}{|c|}{$\begin{array}{c}\text { CHD } \\
(N=6,602)\end{array}$} & \multicolumn{2}{|c|}{$\begin{array}{l}\text { Non-CHD } \\
(N=6,602)\end{array}$} & \multirow[t]{2}{*}{$p$-value } \\
\hline & $n$ & $\%$ & $N$ & $\%$ & \\
\hline Urbanization level & & & & & 1.000 \\
\hline Very high & 2,151 & $33 \%$ & 2,151 & $33 \%$ & \\
\hline High & 3,063 & $46 \%$ & 3,063 & $46 \%$ & \\
\hline Moderate & 944 & $14 \%$ & 944 & $14 \%$ & \\
\hline Low & 444 & $7 \%$ & 444 & $7 \%$ & \\
\hline Income (NTD) & & & & & 1.000 \\
\hline 0 & 2,953 & $45 \%$ & 2,953 & $45 \%$ & \\
\hline $1-15840$ & 1,122 & $17 \%$ & 1,122 & $17 \%$ & \\
\hline $15841-25000$ & 1,921 & $29 \%$ & 1,921 & $29 \%$ & \\
\hline$>25000$ & 606 & $9 \%$ & 606 & $9 \%$ & \\
\hline Comorbidities & & & & & 0.100 \\
\hline \multicolumn{6}{|l|}{ Female infertility } \\
\hline Yes & 330 & $5 \%$ & 290 & $4 \%$ & \\
\hline No & 6,272 & $95 \%$ & 6,312 & $96 \%$ & \\
\hline Fertility & & & & & $<0.001$ \\
\hline 0 & 4,332 & $66 \%$ & 3,902 & $59 \%$ & \\
\hline 1 & 981 & $15 \%$ & 1,073 & $16 \%$ & \\
\hline 2 & 765 & $12 \%$ & 892 & $14 \%$ & \\
\hline$\geqq 3$ & 524 & $8 \%$ & 735 & $11 \%$ & \\
\hline
\end{tabular}

TABLE 2 | Live births, abortions, and fertility of CHD and non-CHD.

\begin{tabular}{|c|c|c|c|c|c|c|c|c|c|c|c|c|c|c|}
\hline \multirow[b]{3}{*}{ Live births } & \multicolumn{3}{|c|}{ CHD $(N=6,602)$} & \multicolumn{7}{|c|}{ Non-CHD $(N=6,602)$} & \multirow{3}{*}{$\begin{array}{c}\text { IRR } \\
0.7402\end{array}$} & \multicolumn{2}{|c|}{$95 \% \mathrm{Cl}$} & \multirow{3}{*}{$\begin{array}{c}\boldsymbol{p} \text {-value } \\
\\
<0.001^{*}\end{array}$} \\
\hline & \multirow{2}{*}{$\begin{array}{c}\text { No. of events } \\
2,835\end{array}$} & \multirow{2}{*}{$\begin{array}{c}\text { PY } \\
90523.1\end{array}$} & \multirow{2}{*}{$\begin{array}{c}\text { IR } \\
313.2\end{array}$} & \multicolumn{2}{|c|}{$95 \% \mathrm{Cl}$} & \multirow{2}{*}{$\begin{array}{c}\text { No. of events } \\
3,898\end{array}$} & \multirow{2}{*}{$\begin{array}{c}\mathbf{P Y} \\
92130.272\end{array}$} & \multirow{2}{*}{$\begin{array}{c}\text { IR } \\
423.1\end{array}$} & \multicolumn{2}{|c|}{$95 \% \mathrm{Cl}$} & & & & \\
\hline & & & & 301.9 & 324.9 & & & & 410.0 & 436.6 & & 0.7053 & 0.7769 & \\
\hline Abortions & 1,566 & 90523.1 & 173.0 & 164.6 & 181.8 & 1,626 & 92130.272 & 176.5 & 168.1 & 185.3 & 0.9802 & 0.9145 & 1.0506 & 0.572 \\
\hline Fertility & 4,401 & 90523.1 & 486.2 & 472.0 & 500.8 & 5,524 & 92130.272 & 599.6 & 584.0 & 615.6 & 0.8109 & 0.7794 & 0.8436 & $<0.001^{*}$ \\
\hline
\end{tabular}

IR, incidence rate per 10,000 person-years; IRR, incidence rate ratio, comparing CHD cohort with the control cohort; PY, person years.

*Statistically significant.

groupings are summarized in Table 3. For more accurate analysis of different CHDs on fertility, we only retrieved the ICD-9 codes of definite CHD diagnosis as mentioned in the methods and excluded some uncertain diagnosis with the beginning words "other" or "unspecified". Some patient might have more than one CHD diagnosis, we grouped patient into simple or severe CHDs according to the most complicated CHD diagnosis she had.

\section{Influence of Varying Severity Levels of CHDs on Live Birth, Abortion, and Fertility Rates}

The influence of different CHD severity on live births, abortions, and fertility are illustrated in Table 4 . There were significantly fewer live births and a significantly lower fertility rate for all CHDs, as compared to non-CHD patients, but the abortion rate did not differ between the groups. A trend was observed in which the live birth rate decreased with increasing CHD severity and complexity, for these two CHD classifications.

\section{Influence of Pulmonary Hypertension of CHDs on Live Birth, Abortion, and Fertility Rates}

We further evaluated the influence of pulmonary hypertension of CHDs on live birth, abortion, and fertility rates in Table 5. During the study period, CHDs with pulmonary hypertension had a significantly lower rate of live births (IRR $0.83,95 \%$ CI $0.73-0.93, p=0.002$ ) than CHDs without pulmonary hypertension, and this trend was even lower among the severe CHDs group combined with pulmonary hypertension (IRR 0.63, $95 \%$ CI $0.40-0.99, p=0.046)$. The abortion rate was similar between the CHDs no matter if they were simple or severe groups, nor they had pulmonary hypertension or not. Similar to live births, fertility was lower in the simple CHDs with pulmonary hypertension (IRR 0.87, 95\% CI 0.78-0.97, $p=0.014$ ). However, severe CHDs with pulmonary hypertension didn't demonstrate significantly different fertility as compared to those without pulmonary hypertension (IRR $0.74,95 \%$ CI $0.53-1.03$, $p=0.074$ ). 
TABLE 3 | The distribution of congenital heart diseases.

\begin{tabular}{|c|c|c|c|}
\hline CHD type & ICD-9-CM & Group & Numbers \\
\hline ASD- $\|^{a}$ & 745,7455 & Simple & 2,657 \\
\hline Ventricular septal defect & 7454 & Simple & 1,415 \\
\hline Patent ductus arteriosus & 7470 & Simple & 516 \\
\hline Congenital stenosis of pulmonary valve & 74602 & Simple & 57 \\
\hline PAPVR ${ }^{b}$ & 74742 & Simple & 10 \\
\hline Common truncus & 7450,74500 & Severe & 61 \\
\hline Transposition of great vessels & $7451,74510,74512$ & Severe & 12 \\
\hline Tetralogy of Fallot & 7452 & Severe & 173 \\
\hline Common ventricle & 7453 & Severe & 14 \\
\hline Endocardial cushion defects & $7456,74560,74569$ & Severe & 36 \\
\hline Anomalies of pulmonary valve/artery & $7460,7473,74600,74601,74609$ & Severe & 97 \\
\hline Tricuspid atresia and stenosis & 7461 & Severe & 6 \\
\hline Ebstein's anomaly & 7462 & Severe & 51 \\
\hline Aortic valve/subaortic stenosis & 7463,74681 & Severe & 68 \\
\hline Congenital insufficiency of aortic valve & 7464 & Severe & 85 \\
\hline Congenital mitral stenosis/insufficiency & 7465,7466 & Severe & 48 \\
\hline Coarctation of aorta/anomalies of aorta & $7471,74710,74711,7472,74720,74721,74722,74729$ & Severe & 87 \\
\hline Double outlet right ventricle & 74511 & Severe & 6 \\
\hline Common atrium & 74561 & Severe & 35 \\
\hline Cor triatriatum & 74682 & Severe & 7 \\
\hline Infundibular pulmonic stenosis & 74683 & Severe & 76 \\
\hline Coronary artery anomaly & 74685 & Severe & 75 \\
\hline Congenital heart block & 74686 & Severe & 12 \\
\hline TAPVR $^{\mathrm{C}}$ & 74741 & Severe & 5 \\
\hline
\end{tabular}

a Ostium secundum type atrial septal defect.

${ }^{b}$ Partial anomalous pulmonary venous connection.

c Total anomalous pulmonary venous connection.

TABLE 4 | The influence of different cardiac structural defects on live births, abortions, and fertility.

\begin{tabular}{|c|c|c|c|c|c|c|c|c|c|c|c|c|}
\hline $\begin{array}{l}\text { Group } \\
\text { Simple CHDs }\end{array}$ & \multicolumn{4}{|c|}{ Live births } & \multicolumn{4}{|c|}{ Abortions } & \multicolumn{4}{|c|}{ Fertility } \\
\hline Severe CHDs & 0.60 & 0.52 & 0.69 & $<0.0001^{*}$ & 1.04 & 0.86 & 1.27 & 0.688 & 0.72 & 0.64 & 0.80 & $<0.0001^{*}$ \\
\hline
\end{tabular}

$I R$, incidence rate per 10,000 person-years; IRR, incidence rate ratio, comparing $C H D$ cohort with the control cohort; PY, person years.

*Statistically significant.

\section{DISCUSSION}

It is estimated that $12-15 \%$ of all pregnancies result in miscarriages, in healthy women $(2,18)$. For women with CHDs, miscarriages have been observed in $6-15 \%$ of all pregnancies $(2$, $7-9,19)$. Stillbirths occur much less commonly than miscarriages. In 2009, the WHO estimated that $0.2-4.7 \%$ (average: $2 \%$ ) of all pregnancies, worldwide, result in stillbirths (20). According to a single-center study in Greece, the offspring mortality rate was $3.7 \%$ higher in the CHD mothers than in the general population (21). Other studies have reported higher rates stillup to $16.8 \%$ - of miscarriages and stillbirths in women with CHDs $(2,7,8,18)$. Nevertheless, it should be noted that precise numbers are obscure because a high percentage of clinically imperceptible miscarriages occurred during early pregnancy in both patient groups.

In this retrospective research of Taiwanese women of reproductive age with $\mathrm{CHDs}$, we discovered those women had lower live birth and fertility rates. Both rates were even minor among the greater CHD severity levels. The observed rates are comparable to a previous study, conducted in Germany, Hungary, and Japan, which reported an overall miscarriage/stillbirth rate of $24.8 \%$, with no significant difference between pregnancies but with different forms of maternal CHDs (22). However, we evaluated the occurrence of giving birth, not the actual numbers of offspring. It is entirely possible 
TABLE 5 | The influence of pulmonary hypertension on live births, abortions, and fertility among different CHDs.

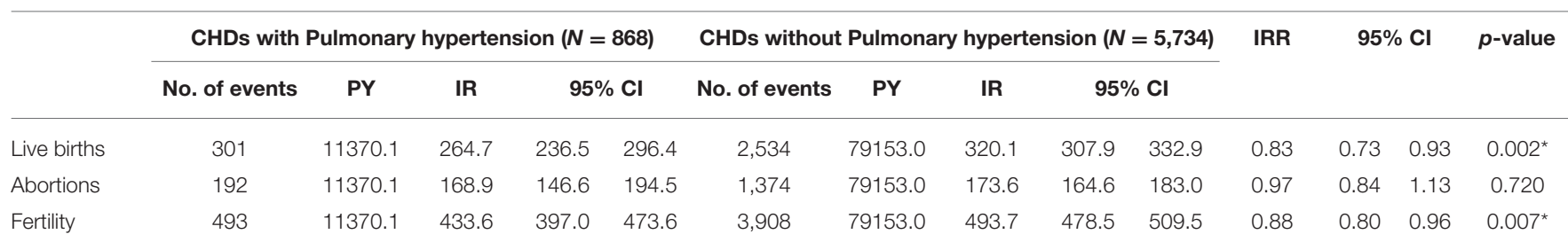

Group1. Simple CHDs

\begin{tabular}{|c|c|c|c|c|c|c|c|c|c|c|c|c|c|c|}
\hline \multirow[b]{2}{*}{ Live births } & \multicolumn{5}{|c|}{ Pulmonary hypertension $(N=640)$} & \multicolumn{5}{|c|}{ No Pulmonary hypertension } & \multirow{2}{*}{$\begin{array}{l}\text { IRR } \\
0.83\end{array}$} & \multicolumn{2}{|c|}{$95 \% \mathrm{Cl}$} & \multirow{2}{*}{$\begin{array}{c}\boldsymbol{p} \text {-value } \\
0.008^{\star}\end{array}$} \\
\hline & $\begin{array}{c}\text { No. of events } \\
233\end{array}$ & $\begin{array}{c}\text { PY } \\
8451.9\end{array}$ & $\frac{\text { IR }}{275.7}$ & 242.5 & 313.4 & $\begin{array}{c}\text { No. of events } \\
1,714\end{array}$ & $\begin{array}{c}\text { PY } \\
51612.3\end{array}$ & $\begin{array}{c}\text { IR } \\
332.1\end{array}$ & 316.7 & 348.2 & & 0.72 & 0.95 & \\
\hline Fertility & 377 & 8451.9 & 446.1 & 403.2 & 493.4 & 2,636 & 51612.3 & 510.7 & 491.6 & 530.6 & 0.87 & 0.78 & 0.97 & $0.014^{\star}$ \\
\hline
\end{tabular}

Group2. Severe CHDs

\begin{tabular}{|c|c|c|c|c|c|c|c|c|c|c|c|c|c|c|}
\hline \multirow[b]{3}{*}{ Live births } & \multicolumn{5}{|c|}{ Pulmonary hypertension $(N=87)$} & \multicolumn{5}{|c|}{ No Pulmonary hypertension } & \multirow{3}{*}{$\begin{array}{l}\text { IRR } \\
0.63\end{array}$} & \multicolumn{2}{|c|}{$95 \% \mathrm{Cl}$} & \multirow{3}{*}{$\begin{array}{c}\boldsymbol{p} \text {-value } \\
0.046^{\star}\end{array}$} \\
\hline & \multirow{2}{*}{$\begin{array}{c}\text { No. of events } \\
20\end{array}$} & \multirow{2}{*}{$\begin{array}{c}\text { PY } \\
1122.7\end{array}$} & \multirow{2}{*}{$\begin{array}{c}\text { IR } \\
178.1\end{array}$} & \multicolumn{2}{|c|}{$95 \% \mathrm{Cl}$} & \multirow{2}{*}{$\begin{array}{c}\text { No. of events } \\
262\end{array}$} & \multirow{2}{*}{$\begin{array}{c}\text { PY } \\
9256.7\end{array}$} & \multirow{2}{*}{$\begin{array}{c}\text { IR } \\
283.0\end{array}$} & \multicolumn{2}{|c|}{$95 \% \mathrm{Cl}$} & & & & \\
\hline & & & & 114.9 & 276.1 & & & & 250.8 & 319.5 & & 0.40 & 0.99 & \\
\hline Abortions & 18 & 1122.7 & 160.3 & 101.0 & 254.5 & 162 & 9256.7 & 175.0 & 150.0 & 204.1 & 0.92 & 0.56 & 1.49 & 0.724 \\
\hline Fertility & 38 & 1122.7 & 338.5 & 246.3 & 465.2 & 424 & 9256.7 & 458.0 & 416.5 & 503.8 & 0.74 & 0.53 & 1.03 & 0.074 \\
\hline
\end{tabular}

IR, incidence rate per 10,000 person-years; IRR, incidence rate ratio, comparing CHD cohort with the control cohort; PY, person years.

*Statistically significant.

that along with the growing number of mothers with CHDs desiring to become pregnant, the numbers of severe and very severe CHD mothers might also rise. In turn, this may lead to a growing number of neonatal complications, including miscarriages and stillbirths.

There is no doubt that pulmonary hypertension is associated with high morbidity and mortality during pregnancy in the literature review (23). However, some large series didn't identify pulmonary hypertension as a predictor of adverse outcome of maternal complications during pregnancy $(9,19)$. This is probably due to low prevalence since women with pulmonary hypertension are generally advised against pregnancy, not to mention severe CHDs with pulmonary hypertension. Severe CHD groups had more complicated hemodynamic disturbances and those could further contribute their worse prognosis rather than pulmonary hypertension only. Those were probably the reasons of no significant difference of fertility between our severe CHD group with or without pulmonary hypertension.

The observed abortion rate was comparable between the $\mathrm{CHD}$ and non-CHD groups. In Marc-André Koerten's study, only $8 \%$ of the observed pregnancies were terminated (22) and around $5-8 \%$ were found to be terminated in other literature $(2,8,24)$. The overall rate of pregnancy termination in CHD women was lower than that for the general public (30 and $22 \%$, respectively). The difference may be attributable to an intensely strong desire to have a child and/or to their fear about future ability to become pregnant or to give birth among women with CHDs.
We observed that the incidence rate of live births and fertility decreased in CHD patients. These findings might be attributable to not only potential effect of CHD itself or associated underlying genetic problems, other extra-cardiac anomalies and medical therapy like anticoagulants on subsequent fertility but also an inability to tolerate childbearing either due to physician recommendation or impact of CHD on patient's reproductive choice. Considering the psychological issue, patients might be afraid of being pregnant because worry about potential adverse impact brought by CHD and its possible complications such as pulmonary hypertension.

\section{LIMITATIONS}

Due to the retrospective database design of the study, it had some limitations. First, the NHIRD does not contain detailed clinical data and, therefore, we could not assess cardiovascular statuses, structure details, and whether patients received any operation/intervention for their cardiac defect. Besides, we didn't analyze any associations of extra-cardiac anomalies and genetic anomalies. It is unknown whether the higher number of stillbirths or abortions is attributable to the occurrence of medical indications for maternal complications or neonatal complications. For the exactitude of the diagnosis entered in the database of the national insurance program and to avoid an overestimation from insignificant or spontaneously resolved cardiac defects, patients with CHDs were enrolled only when 
they had catastrophic illness certificates. Second, information on marital statuses and educations levels are not obtainable from the NHIRD. Medically assisted procreation was either not taken into consideration for simplification of our focus on the congenital heart disease. Nonetheless, marriage is not an essential condition for fertility and we didn't know the willing of having a child in the study. We couldn't either verify if the infertility was probably related to the partner, rather than the women. We matched CHD patients with non-CHD patients, based on urbanization and income, which are highly associated with health care and education levels. Third, some artificial abortion is not covered by the NHI and performed in local clinics, so the data of selffinanced abortion is not retrieved by NHIRD. However, the NHI waives copayment for patients with CHDs and offers affordable care for these patients with CHDs from birth, those CHDs and even complex CHDs should prefer to receive artificial abortion in the official hospital for their safety. These limitations aside, this study is meaningful for a number of reasons: It employed a nationwide, population-based cohort design; had a long followup duration, and an examined data from large number of patients with CHDs, even if patients were treated at different hospitals. To the best of our knowledge, no prior research has explored fertility in women with CHDs.

In conclusion, this pilot research revealed that CHDs compromises live births and female fertility, even for simple forms of CHDs. For all forms of CHDs, it is recommended that pregnant patients should be appeared to and advised individually by multidisciplinary team of pediatric cardiologists, obstetricians, and anesthetists with relevant expertise.

\section{DATA AVAILABILITY STATEMENT}

The original contributions presented in the study are included in the article, further inquiries can be directed to the corresponding author.

\section{REFERENCES}

1. Moons P, Bovijn L, Budts W, Belmans A, Gewillig M. Temporal trends in survival to adulthood among patients born with congenital heart disease from 1970 to 1992 in Belgium. Circulation. (2010) 122:226472. doi: 10.1161/CIRCULATIONAHA.110.946343

2. Drenthen W, Pieper PG, Roos-Hesselink JW, van Lottum WA, Voors AA, Mulder BJ, et al. Outcome of pregnancy in women with congenital heart disease: a literature review. J Am Coll Cardiol. (2007) 49:230311. doi: 10.1016/j.jacc.2007.03.027

3. Yeh SJ, Chen HC, Lu CW, Wang JK, Huang LM, Huang SC, et al. National database study of survival of pediatric congenital heart disease patients in Taiwan. J Formos Med Assoc. (2015) 114:159-63. doi: 10.1016/j.jfma.2012.10.006

4. Group JCSJW. Guidelines for Indication and Management of Pregnancy and Delivery in Women with Heart Disease (JCS 2010): digest version. Circ J. (2012) 76:240-60. doi: 10.1253/circj.CJ-88-0023

5. Thorne S, MacGregor A, Nelson-Piercy C. Risks of contraception and pregnancy in heart disease. Heart. (2006) 92:15205. doi: 10.1136/hrt.2006.095240

6. Trigas V, Nagdyman N, Pildner von Steinburg S, Oechslin E, Vogt M, Berger F, et al. Pregnancy-related obstetric and cardiologic problems in women after

\section{ETHICS STATEMENT}

The studies involving human participants were reviewed and approved by Institutional Review Board of Chang Gung Medical Foundation (IRB No. 1906140058). Written informed consent from the participants' legal guardian/next of kin was not required to participate in this study in accordance with the national legislation and the institutional requirements.

\section{AUTHOR CONTRIBUTIONS}

S-JC, Y-JL, M-HL, and C-FH contributed to conception and design of the study. S-JC organized the database and wrote the first draft of the manuscript. Y-HY performed the statistical analysis. All authors contributed to manuscript revision, read, and approved the submitted version.

\section{FUNDING}

This study was supported in part by grants from Chang Gung Memorial Hospital (CFRPG8H0221, CFRPG8J0121). However, this institution did not influence the study design, data collection, analysis, decision to publish, or preparation of the manuscript.

\section{ACKNOWLEDGMENTS}

We would like to thank Ya-Han Shen, Hsin-Yi Chien, and ChihYun Lin, and the Biostatistics Center of Kaohsiung Chang Gung Memorial Hospital for contributing to the statistical analyses. We would also like to acknowledge the Health Information and Epidemiology Laboratory of Chia-Yi Chang Gung Memorial Hospital for their constructive comments on the research and their assistance in data analysis.

atrial switch operation for transposition of the great arteries. Circ J. (2014) 78:443-9. doi: 10.1253/circj.CJ-12-1051

7. Siu SC, Colman JM, Sorensen S, Smallhorn JF, Farine D, Amankwah $\mathrm{KS}$, et al. Adverse neonatal and cardiac outcomes are more common in pregnant women with cardiac disease. Circulation. (2002) 105:217984. doi: 10.1161/01.CIR.0000015699.48605.08

8. Khairy P, Ouyang DW, Fernandes SM, Lee-Parritz A, Economy KE, Landzberg MJ. Pregnancy outcomes in women with congenital heart disease. Circulation. (2006) 113:517-24. doi: 10.1161/CIRCULATIONAHA.105.589655

9. Drenthen W, Boersma E, Balci A, Moons P, Roos-Hesselink JW, Mulder BJ, et al. Predictors of pregnancy complications in women with congenital heart disease. Eur Heart J. (2010) 31:2124-32. doi: 10.1093/eurheartj/ehq200

10. European Society of G, Association for European Paediatric C, German Society for Gender M, Regitz-Zagrosek V, Blomstrom Lundqvist C, Borghi C, et al. ESC Guidelines on the management of cardiovascular diseases during pregnancy: the Task Force on the Management of Cardiovascular Diseases during Pregnancy of the European Society of Cardiology (ESC). Eur Heart J. (2011) 32:3147-97. doi: 10.1093/eurheartj/ehr218

11. Lu CW, Shih JC, Chen SY, Chiu HH, Wang JK, Chen CA, et al. Comparison of 3 risk estimation methods for predicting cardiac outcomes in pregnant women with congenital heart disease. Circ J. (2015) 79:160917. doi: $10.1253 /$ circj.CJ-14-1368 
12. Pieper PG, Hoendermis ES. Pregnancy in women with pulmonary hypertension. Neth Heart J. (2011) 19:504-8. doi: 10.1007/s12471-011-0219-9

13. Pan ML, Chen LR, Tsao HM, Chen KH. Relationship between polycystic ovarian syndrome and subsequent gestational diabetes mellitus: a nationwide population-based study. PLoS ONE. (2015) 10:e0140544. doi: 10.1371/journal.pone.0140544

14. Ko KY, Yen RF, Lin CL, Cheng MF, Huang WS, Kao CH. Pregnancy outcome after I-131 therapy for patients with thyroid cancer: a nationwide population-based cohort study. Medicine (Baltimore). (2016) 95:e2685. doi: 10.1097/MD.0000000000002685

15. Warnes CA, Liberthson R, Danielson GK, Dore A, Harris L, Hoffman JI, et al. Task force 1: the changing profile of congenital heart disease in adult life. J Am Coll Cardiol. (2001) 37:1170-5. doi: 10.1016/S0735-1097(01)01272-4

16. Wu MH, Chen HC, Lu CW, Wang JK, Huang SC, Huang SK. Prevalence of congenital heart disease at live birth in Taiwan. J Pediatr. (2010) 156:7825. doi: 10.1016/j.jpeds.2009.11.062

17. Mathai SC, Hemnes AR, Manaker S, Anguiano RH, Dean BB, Saundankar $\mathrm{V}$, et al. Identifying patients with pulmonary arterial hypertension using administrative claims algorithms. Ann Am Thorac Soc. (2019) 16:797806. doi: 10.1513/AnnalsATS.201810-672CME

18. Garcia-Enguidanos A, Calle ME, Valero J, Luna S, Dominguez-Rojas V. Risk factors in miscarriage: a review. Eur J Obstet Gynecol Reprod Biol. (2002) 102:111-9. doi: 10.1016/S0301-2115(01)00613-3

19. Siu SC, Sermer M, Colman JM, Alvarez AN, Mercier LA, Morton BC, et al. Prospective multicenter study of pregnancy outcomes in women with heart disease. Circulation. (2001) 104:515-21. doi: 10.1161/hc3001.0 93437

20. Cousens S, Blencowe H, Stanton C, Chou D, Ahmed S, Steinhardt L, et al. National, regional, and worldwide estimates of stillbirth rates in 2009 with trends since 1995: a systematic analysis. Lancet. (2011) 377:1319-30. doi: 10.1016/S0140-6736(10)6 2310-0

21. Ntiloudi D, Zegkos T, Bazmpani MA, Parcharidou D, Panagiotidis T, Hadjimiltiades S, et al. Pregnancy outcome in women with congenital heart disease: A single-center experience. Hellenic J Cardiol. (2018) 59:1559. doi: 10.1016/j.hjc.2017.08.008

22. Koerten MA, Niwa K, Szatmari A, Hajnalka B, Ruzsa Z, Nagdyman N, et al. Frequency of miscarriage/stillbirth and terminations of pregnancy among women with congenital heart disease in Germany, Hungary and Japan. Circ J. (2016) 80:1846-51. doi: 10.1253/circj.CJ-15-1296

23. Weiss BM, Zemp L, Seifert B, Hess OM. Outcome of pulmonary vascular disease in pregnancy: a systematic overview from 1978 through 1996. J Am Coll Cardiol. (1998) 31:1650-7. doi: 10.1016/S0735-1097(98)00162-4

24. Sedgh G, Singh S, Shah IH, Ahman E, Henshaw SK, Bankole A. Induced abortion: incidence and trends worldwide from 1995 to 2008. Lancet. (2012) 379:625-32. doi: 10.1016/S0140-6736(11)61786-8

Conflict of Interest: The authors declare that the research was conducted in the absence of any commercial or financial relationships that could be construed as a potential conflict of interest.

Copyright (C) 2021 Chien, Lin, Lo, Huang and Yang. This is an open-access article distributed under the terms of the Creative Commons Attribution License (CC BY). The use, distribution or reproduction in other forums is permitted, provided the original author(s) and the copyright owner(s) are credited and that the original publication in this journal is cited, in accordance with accepted academic practice. No use, distribution or reproduction is permitted which does not comply with these terms. 